\title{
Synthesis of Iron Oxide Yellow from Spent Pickling Solutions
}

\author{
Guangqin WAN ${ }^{1, \mathrm{a},}{ }^{*}$, Feifei $\mathrm{LV}^{1, \mathrm{~b}}$, Yaqiang $\mathrm{YANG}^{1, \mathrm{c}}$ and Xingyao WANG ${ }^{1, \mathrm{~d}}$ \\ ${ }^{1}$ Department of Chemistry, School of Science, Tianjin University, Tianjin, China \\ awangq627@163.com, , ${ }^{\mathrm{a}} \mathrm{mrhsyu@163.com,}{ }^{\mathrm{c}} 15822212057 @ 163 . c o m,{ }^{\mathrm{d}}$ wxyghw@tju.edu.cn
}

\begin{abstract}
This paper demonstrates a simple environment-friendly synthesis route of iron oxide yellow ( $\alpha-\mathrm{FeOOH})$ using spent pickling solutions as raw material. After abundant laboratory experiments, we finally pinned down the best procedure. The research showed that $\alpha-\mathrm{FeOOH}$ nanometer material with average diameter of $50 \mathrm{~nm}$ and average length of $400 \mathrm{~nm}$ was prepared at the optimal technique. And the $\mathrm{FeOOH}$ content of the sample was as high as $90 \%$, which is higher than the $86 \%$ of GB/T1863-2008. The structure, morphology and size distribution of the product was characterized by X-ray diffraction (XRD), Transmission electron microscope (TEM), Scanning electron microscope (SEM) and Malvern lazer particle analyzer, respectively. The test results show that all the indices of as-prepared iron oxide yellow are completely in conformity with and even better than national primes standard.
\end{abstract}

\section{Introduction}

As we all know, pickling is an essential surface cleaning treatment for chemically removing a scale layer of iron oxides on steel surface. If discharged directly without previous treatment, the spent pickling solutions would do great damage to environment due to their high concentrations of iron and residual acid which are hazardous. Different processes have been reported for the treatment of steel pickling waste liquid in literatures which include: neutralization/precipitation ${ }^{[1]}$; hydrothermal method ${ }^{[2,3]}$; spray roasting ${ }^{[4,5]}$; spray pyrolysis $^{[6]}$; electrolytic precipitation/deposition ${ }^{[7,8]}$; coprecipitation ${ }^{[9,10]}$; ion exchange technique $^{[11]}$; acid pressure leaching ${ }^{[12]}$; electro-dialysis/membrane separation ${ }^{[13]}$. There is no doubt that these approaches recover acid and metallic values respectively. However, most operation conditions of these methods are demanding, complex and costly, so it is hard to accomplish industrialization when taking practical application into consideration. Therefore, it is imperative for us to find an effective method to take full advantage of iron ion dissolved in disposal pickling solutions.

However, iron oxide yellow pigment, also known as goethite $(\alpha-\mathrm{FeOOH})$, as one of the most widely used and profitable material which exhibit various merits including good dyeing force, excellent covering power, heat-proofing, acid resistance, resistance to solvent, non-poison, anti-rust, ect, has aroused a wide range of concern of different fields. These outstanding properties make iron oxide yellow receives considerable interest among

*Corresponding author:wangq627@163.com 
researchers for the potential application in the areas of coating, ceramic, plastic, robber as well as cosmetics, food, adhesion agent. From this point of view, it appears that research on the preparation of iron oxide yellow pigment is not only significant but also a rewarding and deserving causes. So far, many measures have been developed to fabricate goethite $(\alpha-\mathrm{FeOOH})$ such as forced hydrolysis ${ }^{[14,15]}$; microemulsion ${ }^{[16]}$; chemical precipitation ${ }^{[17,18]}$; the sol-gel method ${ }^{[19]}$; electrodeposition ${ }^{[20,21]}$; the hydrothermal technique ${ }^{[22]}$, etc. Recently, with growing concern of environment protection and with the increase by a large quantity of demand for iron oxide yellow pigment, more and more manufactures begin to turn to grope for new ways to produce more competitive products by using low-cost raw materials such as spent pickle liquor, pyrite cinder. Though some achievements have been made, it is still hard for them to manufacture high-quality goethite $(\alpha-\mathrm{FeOOH})$. Our group has been engaged in working on the treatment of waste acid for years. After persistent efforts, we finally succeeded in discovering a novel approach to transform spent pickling solutions into worthwhile and profitable product, namely iron oxide yellow. The result revealed that high quality goethite can be gained under appropriate conditions. The properties of the product perfectly meet national primes standard of GB/T1863-2008.

Not only can this procedure utilizes ferrous iron dissolved in the spent pickle liquors to produce high value-added material, that is iron oxide yellow, but also eliminate the contamination resulted from spent pickling solutions, which poses a serious threat to our ecological environment owing to its high metal content and destructive caustic. Hence, if this process could be advocated throughout the country, it would result in considerable economic and environmental benefits.

\section{Experimental}

The chloride pickling liquors were obtained from a large-scale steel factory in Hebei. The spent pickling liquors were reduced by iron power or scrap iron so that ferric iron in the spent pickling liquors was reduced to ferrous iron first. After the waste acid reacted completely with scrap iron, the reduced mixture was filtered. Then $\mathrm{NH}_{3} \cdot \mathrm{H}_{2} \mathrm{O}$ was slowly added into the constant well-stirred filtrate at $60^{\circ} \mathrm{C}$ until the $\mathrm{pH}$ of the final solution was adjusted to the desired $\mathrm{pH}$ 5.0, where most impurities, such as $\mathrm{Si}, \mathrm{Al}, \mathrm{Mg}, \mathrm{Bi}, \mathrm{Cr}$, would turn into precipitate that could be removed by filtered. The filtrate was diluted with water to $0.3 \mathrm{~mol} / \mathrm{L}$ of $\mathrm{Fe}^{2+}$, into which twenty-five percent $\mathrm{NH}_{3} \cdot \mathrm{H}_{2} \mathrm{O}$ was added dropwise until the $\mathrm{pH}$ of reaction system reached 7.2. Next, air was bubbled into the solution for about 3 hours at a stirring speed of $400 \mathrm{rpm}$ when the low temperature was limited within $10 \sim 30^{\circ} \mathrm{C}$, ferric yellow crystal seed was gained. The second oxidation of ferric yellow crystal seed, which has temperature optima of $75-85^{\circ} \mathrm{C}$ and air flow rate optima for reaction of $0.1 \sim 0.12 \mathrm{~m}^{3} / \mathrm{h}$, resulted in the formation of ferric yellow by a stir treatment of the mixture at the speed of $400 \mathrm{rpm}$ for about $7 \mathrm{~h}$. Ferric yellow was then filtered and washed with distilled water many times to eliminate residual $\mathrm{CL}^{-}$. The single phase $\alpha-\mathrm{FeOOH}$ with excellent pigment property was prepared when as-prepared ferric yellow was exposed to dry in the oven at $75^{\circ} \mathrm{C}$ for 8 hours.

The morphology, structure and size distribution of the product were characterized by Transmission electron microscope (TEM) ( 100CX-II made by JEOL, Tokyo, Japan ), Field emission scanning electron microscope (FESEM, Nanosem 430), X-ray diffraction (XRD) ( BDX-3300 made by Peking University Instrument Co., China), Malvern lazer particle analyzer (MASTERSIZE S MAM 5005 made by Malvern). The test results show that all the indices of as-prepared ferric oxide are quite up to and even better than national prime standard. 


\section{Results and Discussion}

To demonstrate the influence of this cleaning treatment on the spent pickling liquors, table 1 shows the difference of content and ingredients between original spent pickling solutions and purified spent pickling solutions. The purification of waste acid can achieve the elimination of the main impurity ions in the case of $\mathrm{Si}, \mathrm{Al}, \mathrm{Bi}, \mathrm{Ni}, \mathrm{Cr}$, for which the existence makes adverse effects to the quality of the product and the content must be limited in a certain range. From the experimental data we can infer that the concentrations of the other ions, especially for $\mathrm{Si}, \mathrm{Ni}, \mathrm{Al}, \mathrm{Mn}$, which have a great advantage to the synthesis of iron oxide yellow pigment, have dropped off sharply while the content of $\mathrm{Fe}^{2+}$ increased.

TABLE1 CHEMICAL ANALYSIS OF THE STARTING AND PURIFIED SPENT PICKLING LIQUORS

\begin{tabular}{|c|c|c|}
\hline element & $\begin{array}{c}\text { content before } \\
\text { impurity } / \mathrm{mg} \cdot \mathrm{mL}^{-1}\end{array}$ & $\begin{array}{c}\text { content after } \\
\text { purification } / \mathrm{mg} \cdot \mathrm{mL}^{-1}\end{array}$ \\
\hline $\mathrm{Mn}$ & 2.8364 & 0.0782 \\
\hline $\mathrm{Al}$ & 0.3196 & 0.0779 \\
\hline $\mathrm{Bi}$ & 0.0096 & -0.0052 \\
\hline $\mathrm{Si}$ & 0.2602 & 0.1691 \\
\hline $\mathrm{Ni}$ & 0.1084 & 0.0027 \\
\hline $\mathrm{Mg}$ & 0.2062 & 0.0782 \\
\hline $\mathrm{Ca}$ & 0.7968 & 0.4702 \\
\hline $\mathrm{Cu}$ & 0.0315 & 0.0038 \\
\hline $\mathrm{Cr}$ & 0.1324 & 0.0292 \\
\hline
\end{tabular}

The specimen was identified with $\mathrm{X}$-ray diffraction using $\mathrm{Cu} \mathrm{K} \alpha$ radiation ranging from $2 \theta=10$ to $80^{\circ}$ at a scanning rate of $6^{\circ} / \mathrm{min}$. Fig. 1a shows the X-ray diffraction (XRD) patterns of as-synthesized product. As we can see, the XRD peaks position of the synthesized sample matched quite well with the reported values from the standard card and the patterns correspond to goethite phase with orthorhombic crystal structure $(\alpha-\mathrm{FeOOH})$. From the picture, we can observe that shapes of the peaks are extremely sharp, which indicates the high crystallinity of the sample prepared by this method. And the $\mathrm{FeOOH}$ content of the sample was as high as $90 \%$.

Fig. $1 \mathrm{~b}$ exhibits line chart of size distribution of $\alpha-\mathrm{FeOOH}$ product. From fig. $1 \mathrm{~b}$ we can clearly see that the particle size distribution curves of the sample is sharp, which indicates the uniformity in size of goethite particles, and the particle size of the product is mainly between 150 and $400 \mathrm{~nm}$. This is eligible for the iron oxide yellow standard.

Fig. 2 presents the SEM and TEM images of as-prepared $\alpha-F e O O H$ product. Fig. $2 \mathrm{a}$ and $b$ show TEM images of the $\alpha-F e O O H$ at different magnifications. Fig. $2 \mathrm{c}$ and $d$ show SEM images of the $\alpha-\mathrm{FeOOH}$ at different magnifications. As can be seen, the morphology of the resultant $\alpha-\mathrm{FeOOH}$ particles was approximately needle-like or spindle with average diameter of $50 \mathrm{~nm}$ and average length of $400 \mathrm{~nm}$, respectively. The aspect ratio of the corresponding product lies in the range of about $8-10 . \alpha-\mathrm{FeOOH}$ particles have narrow and uniform particle size distribution. 

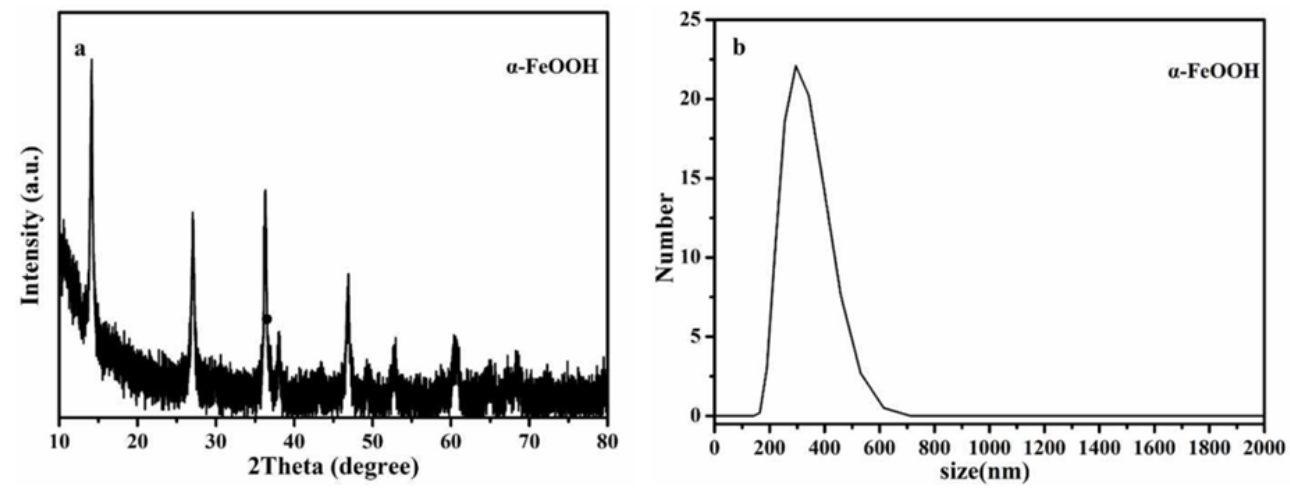

Fig. 1a X-ray diffraction patterns of $\alpha-\mathrm{FeOOH}$ and fig. $1 \mathrm{~b}$ size distribution of $\alpha-\mathrm{FeOOH}$. $\alpha$-FeOOH was prepared at the optimal technique: preparation of ferric yellow crystal seed: $\mathrm{cFe}^{2+}=0.3 \mathrm{moL} / \mathrm{L}$, $\mathrm{pH}=7.2, \mathrm{t}=3 \mathrm{~h}$, temperature is $15^{\circ} \mathrm{C}$, air flow rate is $0.1 \mathrm{~m} / \mathrm{h}$; preparation of ferric yellow:

$\mathrm{cFe}^{2+}=0.3 \mathrm{moL} / \mathrm{L}, \mathrm{pH}=2.4 \sim 3.7, \mathrm{t}=7 \mathrm{~h}$, temperature is $80^{\circ} \mathrm{C}$, air flow rate is $0.12 \mathrm{~m}^{3} / \mathrm{h}$.

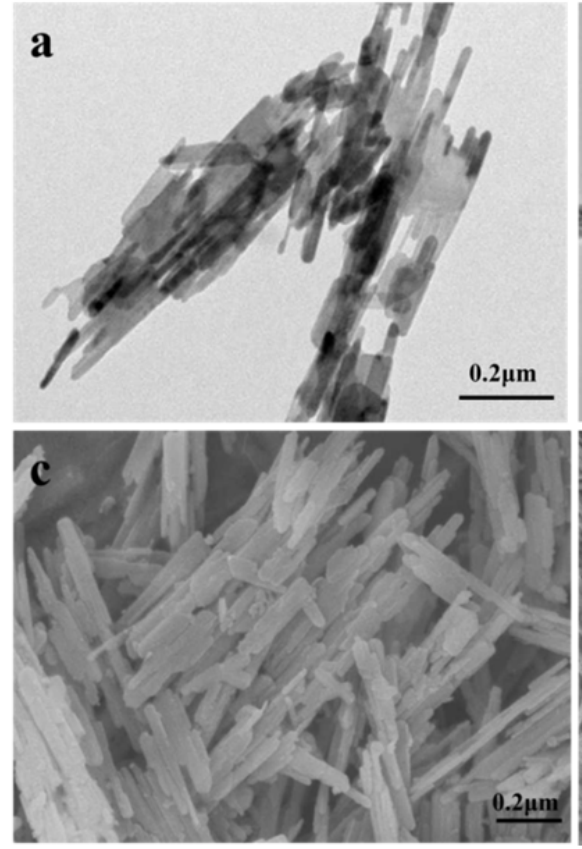

Fig. 2a and $\mathrm{b}$ TEM image of $\alpha-\mathrm{FeOOH}$ sample;
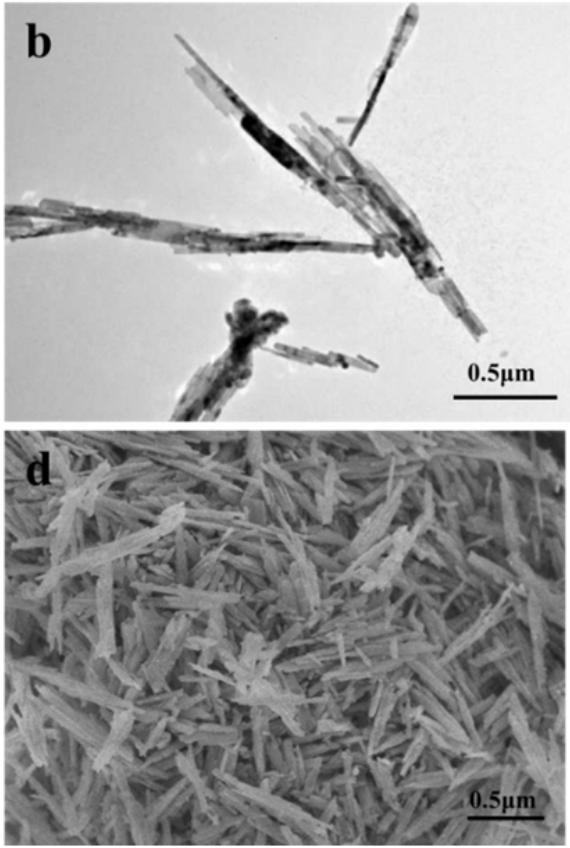

Fig. 2c and d SEM image of $\alpha-\mathrm{FeOOH}$ sample.

$\alpha$-FeOOH was prepared at the optimal technique: preparation of ferric yellow crystal seed: $\mathrm{cFe}^{2+}=0.3 \mathrm{moL} / \mathrm{L}, \mathrm{pH}=7.2, \mathrm{t}=3 \mathrm{~h}$, temperature is $15^{\circ} \mathrm{C}$, air flow rate is $0.1 \mathrm{~m}^{3} / \mathrm{h}$; preparation of ferric yellow: $\mathrm{cFe}^{2+}=0.3 \mathrm{moL} / \mathrm{L}, \mathrm{pH}=2.4 \sim 3.7, \mathrm{t}=7 \mathrm{~h}$, temperature is $80^{\circ} \mathrm{C}$, air flow rate is $0.12 \mathrm{~m}^{3} / \mathrm{h}$.

\section{Summary}

A novel and environment-friendly route was proposed to translate steel pickling waste liquids into high value-added material, namely iron oxide yellow. After purification, the harmful ions in the solutions were greatly reduced which was believed to be favorable to 
the preparation of desired product. $\alpha-\mathrm{FeOOH}$ nanoparticles with orthorhombic crystal structure of goethite were successfully synthesized after the intermediate ferric yellow was exposed to dry in the oven at $75^{\circ} \mathrm{C}$ for 8 hours. The as-synthesized nanometer $\mathrm{FeOOH}$ exhibits excellent pigment property that can be ascribed to the well monodispersity and narrow particle size distribution within $150-400 \mathrm{~nm}$. The content of $\mathrm{FeOOH}$ in the resultant product was as high as $90 \%$, which is perfectly meet national prime standard of GB1863-2008. Thus, it is likely to produce tremendous economic and environmental benefits if the process proposed by us can be implemented throughout the country.

\section{References}

1. A. Lopez-Delgoda, F.J. Alguacil, F.A. Lopez, Recovery of iron from bio-oxidized sulphuric pickling waste water by precipitation as basic sulphates, Hydrometallurgy 45 (1997) 97-112.

2. V.S.T. Ciminelli, A. Dias, H.C. Braga, Simultaneous production of impurity-free water and magnetite from steel pickling liquors by microwave-hydrothermal processing, Hydrometallurgy 84 (2006) 37-42.

3. T. Ozdemir, C. Oztin, N.S. Kincal, Treatment of waste pickling liquors: process synthesis and economic analysis, Chem. Eng. Commun. 193 (2006) 548-563.

4. M. Schiemann, S. Wirtz, V. Scherer, F. Barhold, Spray roasting of iron chloride $\mathrm{FeCl}_{2}$ : Numerical modelling of industrial scale reactors, Powder Technol. 245 (2013) 70-79.

5. A.S. Ferreira, M.B. Mansur, Statistical analysis of the spray roasting operation for the production of high quality $\mathrm{Fe}_{2} \mathrm{O}_{3}$ from steel pickling liquors, Process Saf. Environ. Prot. 89 (2011) 172-178.

6. B. Kurc1, B. Ebin, S. Gurmen, Production and characterization of submicron hematite $\left(\alpha-\mathrm{Fe}_{2} \mathrm{O}_{3}\right)$ particles by ultrasonic spray pyrolysis method, AIP Conf. Proc. 1569 (2013) 265-268.

7. K. Jozsef, M. Andor, S. Miklos, Method for the cyclic electrochemical processing of sulfuric acid-containing pickle waste liquors, U.S. patent 3,969,207 (1976).

8. U. Kerney, Treatment of spent pickling acid from hot dip galvanising, Res. Conserv. Recycl. 10 (1994) 145-151.

9. M. Darroudi, M. Hakimi, E. Goodarzi, R.K. Oskuee, Superparamagnetic iron oxide nanoparticles (SPIONs): Green preparation, characterization and their cytotoxicity effects, Ceramics International 40 (2014) 14641-14645.

10. K.A. Kraus, F. Nelson, J.F. Baxter, Anion-exchange studies. Separation of sulfuric acid from metal sulfates by anion exchange, J. Am. Chem. Soc. 75 (1953) 2768-2770.

11. S. Langova, D. Matysek, Zinc recovery from steel-making wastes by acid pressure leaching and hematite precipitation, Hydrometallurgy 101 (2010) 171-173.

12. F. Rogener, M. Sartor, A. Ban, D. Buchloh, T. Reichardt, Metal recovery from spent stainless steel pickling solutions, Resources, Conservation and Recycling 60 (2012) $72-77$.

13. J.C. Villalba , S. Berezoski, K.D.A. Cavicchiolli, V. Galvani, F.J. Anaissi, Structural refinement and morphology of synthetic akaganèite crystals, $[\beta-\mathrm{FeO}(\mathrm{OH})]$, Mater. Lett. 104 (2013) 17-20.

14. M. Ristic, S. Music, M. Godec, Properties of $\gamma-\mathrm{FeOOH}, \alpha-\mathrm{FeOOH}$ and $\alpha-\mathrm{Fe}_{2} \mathrm{O}_{3}$ particles precipitated by hydrolysis of $\mathrm{Fe}^{3+}$ ions in perchlorate containing aqueous solutions, J. Alloys Compd. 417 (2006) 292-299.

15. S. Bashir, R.W. McCabe, C. Boxall, M.S. Leaver, D. Mobbs, Synthesis of $\alpha$ - and $\beta$-FeOOH iron oxide nanoparticles in non-ionic surfactant medium, J. Nanopart Res. 
11 (2009) 701-706.

16. F.X. Geng, Z.G Zhao, H.T Cong, J.X. Geng, H.M. Cheng, An environment-friendly microemulsion approach to $\alpha-\mathrm{FeOOH}$ nanorods at room temperature, Mater. Res. Bull. 41 (2006) 2238-2243.

17. S. Krehula, S. Popovic, S. Music, Synthesis of acicular a-FeOOH particles at a very high pH, Mater. Lett. 54 (2002) 108-113.

18. A. Jaiswal, S. Banerjee, R. Mani, M.C. Chattopadhyaya, Synthesis, characterization and application of goethite mineral as an adsorbent, J. Environ. Chem. Eng. 1 (2013) 281-289.

19. L. Duraesa, B.F.O. Costa, J. Vasques, J. Campos, A. Portugal, Phase investigation of as-prepared iron oxide/hydroxide produced by sol-gel synthesis, Mater. Lett. 59 (2005) 859-863.

20. L. Martinez, D. Leinen, F. Martín, M. Gabas, J.R. Ramos-Barrado, E. Quagliata, E.A. Dalchiele, Electrochemical Growth of Diverse Iron Oxide $\left(\mathrm{Fe}_{3} \mathrm{O}_{4}, \alpha-\mathrm{FeOOH}\right.$, and $\gamma-\mathrm{FeOOH})$ Thin Films by Electrodeposition Potential Tuning, J. Electrochem. Soc. 154 (2007) D126-D133.

21. S.H. Jiao, L.F. Xu, K.L. Hu, J.J. Li, S. Gao, D.S. Xu, Morphological Control of $\gamma$-FeOOH Nanostructures by Electrodeposition, J. Phys. Chem. C 114(2010) 269-273.

22. D.E. Zhang, X.J. Zhang, X.M. Ni, H.G. Zheng, Preparation and characterization of $\alpha-\mathrm{FeOOH}$ nanorods via an ethylenediamine-assisted route, Mater. Lett. 60 (2006) 1915-1917. 